\title{
Site Location of Projects in China by Clean Development Mechanism: An Input Output Analysis*
}

\author{
Sungin NA ${ }^{1}$, Kiyoshi FUJIKAWA ${ }^{2}$, Tadashi HAYASHI ${ }^{3}$, Kazuhiro UETA ${ }^{4}$, \\ Yoshihisa INADA ${ }^{5}$, Akihisa MORI ${ }^{4}$, Takasei KUSUBE ${ }^{6}$ and Mitsuru SHIMODA ${ }^{7}$ \\ ${ }^{1}$ Hiroshima-Shudo University \\ ${ }^{2}$ Nagoya University \\ ${ }^{3}$ Takasaki City University of Economics \\ ${ }^{4}$ Kyoto University \\ ${ }^{5}$ Konan University \\ ${ }^{6}$ Ishikawa Prefecture University \\ ${ }^{7}$ Applied Research Institute, inc.
}

Received October 24, 2006; final version accepted June 3, 2007

\begin{abstract}
This paper examines which region in China would be suitable as a location for CDM projects using the MultiRegional Input-Output Table China 2000. The criteria for selection used in this research include such socioeconomic effects as output and employment increase induced by CDM projects, spillover effects of technology transferred by $\mathrm{CDM}$ projects from advanced countries and such environmental effects as reduction of $\mathrm{CO}_{2}$ and $\mathrm{SO}_{2}$ emissions by CDM projects. As a result of simulation analysis, the 'South coast', 'North municipalities', and the 'Central region' were found to be potential candidates as suitable regions for a site of CDM projects based on comprehensive evaluation of the above-mentioned criteria.
\end{abstract}

\section{Introduction}

Ueta et al. (2006) demonstrated that implementing Clean Development Mechanism (hereafter, CDM) ${ }^{1}$ projects in China will bring various kinds of favorable effects. Needless to say, CDM projects in China have large potentiality to reduce emissions of greenhouse gas (hereafter, GHG). And they would assist China's sustainable development by promoting job creation, equalizing income distribution or mitigating local air pollution and health damage in China. Moreover, CDM projects in China could even assist sustainable development in the East Asian region as a whole by mitigating trans-boundary acid thing deposition in the region.

Looking at CDM projects registered in United Nations Framework Convention for Climate Change (hereafter, UNFCCC) by March 2007, China is the largest host country in terms of not only in the projects numbers but also in the expecting amount of Certified Emission Reductions (hereafter, CER). Besides, China has still large potentiality for future CDM projects even though the transaction costs of CDM in China could be rather high. The purpose of this paper then is to examine which region in China would be suitable as a location for CDM projects in case Japanese organizations implement CDM projects in China.

Since the CDM scheme is a kind of foreign direct investment, one purpose of CDM is to get CER by reducing GHG emissions, but CDM has another important purpose of supporting sustainable development in the host countries. In other words, socio-economic effects on employment situation or income distribution are also important as to CDM projects. Although a CDM contract itself is on a private basis, implementation of the project requires approval by the governments of both host and investing countries, as well as the CDM Executive Board of the United Nations. Therefore, governments and private stake-holders of both host and investing countries have to discuss various issues related to the proposed CDM projects.

Incidentally, one of the most difficult issues for a host country, especially such large country as China, would be a location for CDM projects. While there are various points of view in regard to determining a location for CDM projects, they can be broadly classified into two categories: effects in the project-construction phase and those in the project-operating phase. Generally speaking, socio-economic effects are emphasized in the project-construction phase, and environmental improvement effects or resource saving effects are emphasized in the project-operation phase. As for a measure of the socio-economic effects of CDM projects, the most well known would be the "output inducement effect" or the "employment inducement effect" calculated in the framework of input-output (hereafter, I-O) analysis.

In section 2, we outline the framework of I-O analysis and show an imaginary CDM project that this paper considers taking China as an example of a host country. Naturally a host country tends to prefer a CDM project that has larger economic inducement effects since such a CDM project is expected to contribute sustainable development in the host

\footnotetext{
* This research is financially supported by International Collaboration Project 2004/2005 "sustainable economic growth and structural reform in Japan" of ESRI (Economic and Social research institute) of the Japanese Cabinet Office. http://www.esri.go.jp/en/prj-2004_2005/menu-e.html
} 
Table 1. Correspondence of region and province.

\begin{tabular}{lll}
\hline & Region name & Province name \\
\hline A & North East & 1 Heilongjiang, 2 Jilin, 3 Liaoning \\
B & North Municipalities & 1 Beijing, 2 Tianjin \\
C & North Coast & 1 Hebei, 2 Shandong \\
D & Central Coast & 1 Jiangsu, 2 Shanghai, 3 Zhejiang \\
E & South Coast & 1 Fujian, 2 Guangdong, 3 Hainan \\
F & Central Region & 1 Shanxi, 2 Henan, 3 Anhui, 4 Jiangxi, 5 Hubei, 6Hunan \\
G & North West & 1 Inner-Mongoria, 2 Ningxia, 3 Shaanxi, 4 Gansu, \\
& & 5 Qinghai, 6 Xinjiang \\
H & South West & 1 Guangxi, 2 Chongqin, 3 Guizhou, 4 Tibet, 5 Sichuan,
\end{tabular}

Source: Okamoto and Ihara (eds.) (2004), p. 5.

country. As indicated in $\operatorname{OECD}(2003)$, we consider income distribution as an indicator of sustainable development. As a proxy variable for equalization of income distribution, we used the standard deviation of region-wise output inducement effects of a CDM project. On the other hand, such environmental indicators as $\mathrm{CO}_{2}$ reduction and $\mathrm{SO}_{2}$ reduction by a CDM project are also important in evaluating CDM projects. The estimation methods for such indicators are also explained in section 2 .

It is also natural that a host country's government would expect resource conservation in the country as a result of the approval of a CDM project. In other words, the more resource conservation the CDM project can realize, the more preferable the project is for the host country's sustainable development. Then, in section 3 we introduce an indicator called the "spillover rate of process innovation" as a measure of resource conservation in the project-operating phase. This indicator is to measure how much an innovation can economize resource consumption in the other sectors than this innovation actually occurred.

Moreover, one of the most urgent issues for China' sustainable development is mitigation of local air pollution that has recently been becoming more serious. Therefore, in section 4 we take environmental effects in the operating phase of CDM projects into consideration as another criterion to determine the location of CDM projects. And, in section 5, we will show through a simulation analysis that the location of the projects would affect the total effects of CDM projects.

We use the China Multi-Regional Input-Output Table 2000 (hereafter, "MRIO") compiled by the Institute of Developing Economies (IDE, 2003) in Japan. In this I-O table, China is divided into eight sub-regions as shown in Table 1 and Figure 1. The great feature of these statistics is that the transactions of goods and services including not only intra-regional intermediate inputs but also inter-regional ones are recorded by industry. Industry sectors in the I-O table we use are divided into 17 sectors as shown in Table $2^{2}$.

\section{Economic and Environmental Effects of CDM Projects in the Construction phase}

\subsection{Output inducement effects and $\mathrm{CO2}$ and $\mathrm{SO} 2$ emission inducement effects}

Leontief (1966) showed how input-output tables could be used to consider the relationship among industry-wise demand and gross output. If column vectors of $\mathbf{f}$ and $\mathbf{x}$ respectively represent domestic final demand and domestic gross output, the base equation of I-O analysis is as follows:

$$
\mathbf{x}=(\mathbf{I}-\mathbf{A})^{-1} \mathbf{f}=\mathbf{B} \cdot \mathbf{f}
$$

Equation (1) shows how much of gross output $(\mathbf{x})$ is required in order to satisfy the final demand (f). The element of the matrix $\mathbf{A}$, expressed as $a_{i j}$, is the domestic input coefficient that shows the relationship of the domestic input of $i$ industry to the gross outputs of $j$ industry and a matrix I stands for the identity matrix. The matrix of $(\mathbf{I}-\mathbf{A})^{-1}$ or $\mathbf{B}$ is called 'Leontief's inverse matrix' whose element, expressed as $b_{i j}$, means the induced output of $j$ industry by one-unit increases in the final demand for $i$ industry ${ }^{3}$.

Furthermore, when we assume that employment vector $\mathbf{e}$ is proportional to the gross output, employment induced by final demand $\mathbf{f}$ can be expressed as in equation (2) where a diagonal matrix $\mathbf{E}$ is the matrix of employment coefficients.

$$
\mathbf{e}=\mathbf{E}(\mathbf{I}-\mathbf{A})^{-\mathbf{1}} \mathbf{f}=\mathbf{E} \cdot \mathbf{B} \cdot \mathbf{f}
$$

Based on this Leontief's inverse matrix, we examine the difference of economic and environmental effects of the same size of CDM projects when the CDM projects are implemented in different regions.

The output effect and employment effect of investments in CDM projects are estimated as follows

$$
\begin{aligned}
\Delta \mathbf{x}_{r} & =\mathbf{B} \cdot \boldsymbol{\Delta} \mathbf{f}_{r}, \\
\Delta \mathbf{e}_{r} & =\mathbf{E} \cdot \mathbf{B} \cdot \boldsymbol{\Delta} \mathbf{f}_{r}, r=A, \cdots, H
\end{aligned}
$$




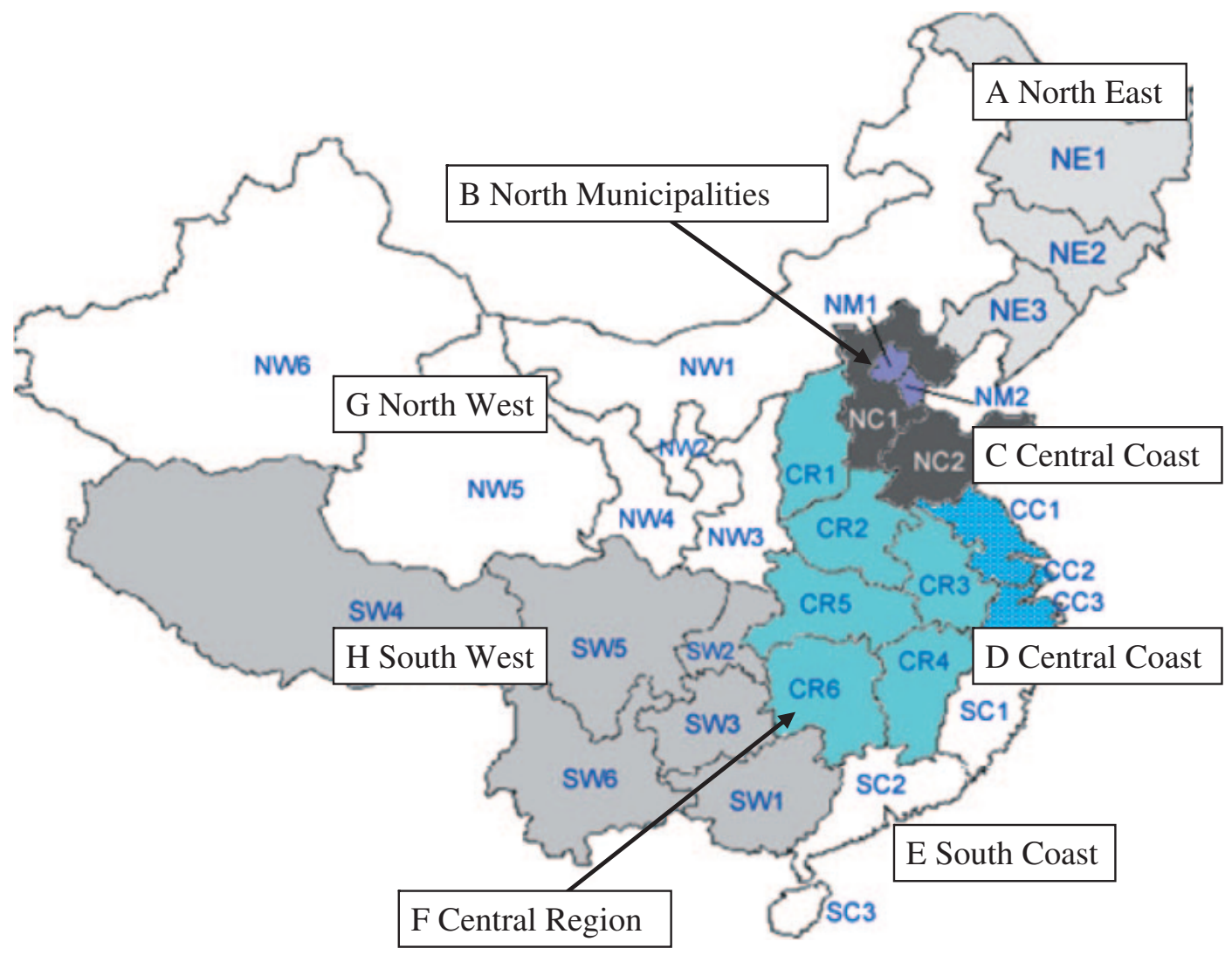

Source: Institute of Developing Economies (2003), p.14.

Fig. 1. Correspondence of region and province.

where $r$ represents each region in the MRIO. The vector $\Delta \mathbf{f}_{r}$ menas the increment of final demands by the investment for a CDM project in $r$ region ${ }^{4}$ and $\Delta \mathbf{x}_{r}$ is the vector of induced output by the CDM project implemented in $r$ region, and $\Delta \mathbf{e}_{r}$ is the vector of induced employment by the same CDM project implemented in $r$ region.

The elements of vector $\boldsymbol{\Delta} \mathbf{f}_{r}$ correspond to construction of coal-burning power plants with a total nominal capacity of 3,000 MW as shown in Table 3. The industrial component of the investment amount was estimated based on the Japanese case carried in the Fixed Capital Formation Table for Input-Output table in Japan, 2000 ${ }^{5}$. The main industries whose goods are demanded by CDM projects are 'Electric machinery' and 'Construction' and the demand for these two industries explains approximately two thirds of the total investment amount.

Next, based on the vector $\Delta \mathbf{x}_{r}$ of output inducement, we can estimate induced $\mathrm{CO}_{2}$ and $\mathrm{SO}_{2}$ emissions as follows:

$$
\begin{aligned}
\Delta \mathbf{c}_{r} & =\mathbf{C} \Delta \mathbf{x}_{r}, \\
\Delta \mathbf{s}_{r} & =\mathbf{S} \Delta \mathbf{x}_{r},
\end{aligned}
$$

where the vectors of $\Delta \mathbf{c}_{r}$ and $\boldsymbol{\Delta} \mathbf{s}_{r}$ respectively stand for the emissions of $\mathrm{CO}_{2}$ and $\mathrm{SO}_{2}$ and $\mathbf{C}$ and $\mathbf{S}$ stand for a diagonal matrix of emission coefficients of $\mathrm{SO}_{2}$ and $\mathrm{CO}_{2}$, respectively. Emission coefficient matrices $\mathbf{C}$ and $\mathbf{S}$ were estimated based on the following statistical data ${ }^{6}$.

- Energy consumption by region and industrial sector: China Energy Statistics Yearbook 2000-2002. Indexes of output values and output amounts: China Statistical Yearbook 2001.

- Conversion factors of calories: China Energy Statistics Yearbook 2000-2002.

- $\mathrm{CO}_{2}$ emission coefficient: National Institute of Science and Technology Policy of Japan (ed.)(1992).

- $\mathrm{SO}_{2}$ emission coefficient: National Institute of Science and Technology Policy of Japan (ed.)(1992).

For $\mathrm{CO}_{2}$ emissions we assumed the same emission coefficient for all regions, while with regard to $\mathrm{SO}_{2}$ emissions we needed to be careful since the sulfur content rates of coal are different among different regions in China ${ }^{7}$. The differences of sulfur content rates were adjusted by regional $\mathrm{SO}_{2}$ emission coefficients. Moreover, those coefficients do not consider waste-gas desulfurization, so emissions of $\mathrm{SO}_{2}$ considered in this research are not 'real emissions' but 'potential emissions, .

\subsection{Economic and environmental characteristics by region in $\mathbf{2 0 0 0}$}

In this section, we review the economic and environmental characteristics in China by region. Table 4 shows 
Table 2. China's sector classification.

\begin{tabular}{|c|c|c|c|}
\hline \multicolumn{2}{|r|}{ 17Sectors } & \multicolumn{2}{|r|}{ Basic sector classification } \\
\hline 1 & Agriculture & 1 & Agriculture \\
\hline \multirow{4}{*}{2} & \multirow{4}{*}{ Mining } & 2 & Coal mining and Processing \\
\hline & & 3 & Crude petroleum and natural gas products \\
\hline & & 4 & Metal ore mining \\
\hline & & 5 & Non-ferrous mineral mining \\
\hline 3 & Food products & 6 & Manufacture of food and tobacco processing \\
\hline \multirow[b]{2}{*}{4} & \multirow[b]{2}{*}{$\begin{array}{l}\text { Textile and wearing } \\
\text { apparel }\end{array}$} & 7 & Textile goods \\
\hline & & 8 & $\begin{array}{l}\text { Wearing apparel, leather, furs, down and related } \\
\text { products }\end{array}$ \\
\hline 5 & Wooden products & 9 & Sawmills and furniture \\
\hline 6 & Paper and printing & 10 & $\begin{array}{l}\text { Paper and products, printing and record medium } \\
\text { reproduction }\end{array}$ \\
\hline \multirow[b]{2}{*}{7} & \multirow[b]{2}{*}{ Chemical products } & 11 & Petroleum processing and coking \\
\hline & & 12 & Chemicals \\
\hline 8 & $\begin{array}{l}\text { Non-metal mineral } \\
\text { products }\end{array}$ & 13 & Nonmetal mineral products \\
\hline \multirow{2}{*}{9} & \multirow[b]{2}{*}{ Metal products } & 14 & Metals smelting and pressing \\
\hline & & 15 & Metal products \\
\hline 10 & Machinery & 16 & Machinery and equipment \\
\hline 11 & Transport equipment & 17 & Transport equipment \\
\hline \multirow{2}{*}{12} & \multirow{2}{*}{ Electronic products } & 18 & Electric equipment and machinery \\
\hline & & 19 & Electric and telecommunication equipment \\
\hline \multirow{4}{*}{13} & \multirow{4}{*}{$\begin{array}{l}\text { Other manufacturing } \\
\text { products }\end{array}$} & 20 & Instruments, meters, cultural and office machinery \\
\hline & & 21 & Maintenance and repair of machine and equipment \\
\hline & & 22 & Other manufacturing products \\
\hline & & 23 & Scrap and waste \\
\hline \multirow{3}{*}{14} & \multirow{3}{*}{$\begin{array}{l}\text { Electricity, gas } \\
\text { and water supply }\end{array}$} & 24 & Electricity, steam and hot water production \\
\hline & & 25 & Gas production and supply \\
\hline & & 26 & Water production and supply \\
\hline 15 & Construction & 27 & Construction \\
\hline \multirow{2}{*}{16} & \multirow{2}{*}{ Trade and transport } & 28 & Transport and warehousing \\
\hline & & 29 & Wholesale and retail trade \\
\hline 17 & Services & 30 & Services \\
\hline
\end{tabular}

Source: Institute of Developing Economies (2003), p. 24.

the region-wise gross output (proxy variable of income) and region-wise emissions of $\mathrm{CO}_{2}$ and $\mathrm{SO}_{2}$ in the year 2000 . The national total gross output is 19,984 billion RMB. The 'Central Coast', 'South Coast' and 'North Coast' account for $23.1 \%, 14.9 \%$ and $14.3 \%$ respectively, so that the total of these three costal regions account for more than half of the national total output ${ }^{9}$. The economic size of the 'Central Region' is also large at $17.5 \%$.

According to the recent China's rapid economic growth, China's energy consumption also increased rapidly and the total emissions of $\mathrm{CO}_{2}$ and $\mathrm{SO}_{2}$ respectively became as much as 944.1 million ton-C and 9.2 million ton in 2000 . As for the regional distribution of $\mathrm{CO}_{2}$ emissions, the 'Central Region', 'Central Coast' and 'North Coast' accounts for 32.7\%, $14.2 \%$, and $12.9 \%$ respectively. Among them, emissions in the 'Central Region' are extremely large. On the other hand, regarding $\mathrm{SO}_{2}$ emissions, the 'Central region', 'Central Coast' and 'North Coast' account for $21.6 \%, 16.1 \%$, and $15.6 \%$ respectively. The reason why the regional distribution of $\mathrm{CO}_{2}$ and $\mathrm{SO}_{2}$ emissions is not same as that of the gross output is that energy consumption pattern and industrial structures are not conformable among regions. Next, let us look at the emission coefficients. The national average of $\mathrm{CO}_{2}$ emission coefficients (national total $\mathrm{CO}_{2}$ emissions / national total output in China) is 47.2 ton- $\mathrm{C} /$ million RMB and the regions where $\mathrm{CO}_{2}$ coefficients exceeded the national average are such four regions as 'Central Region', 'North West', 'North Municipalities', and 'North East'. In other words, carbon intensity in these regions is larger than that in other regions. On the other hand, the national average of $\mathrm{SO}_{2}$ emission coefficients is 0.46 ton/million RMB and the regions whose $\mathrm{SO}_{2}$ coefficients exceeded the national average are such five regions as 'North West', 'North Municipalities', 'North East', 'Central Region' and 'North Coast'. In these regions, the share of coal is relatively large in the energy consumption besides the sulfur content in the consumed coal is relatively high.

\subsection{Simulation analysis on Economic and Environmental Effects of CDM investment in China's power sector in the Construction Phase}

On the basis of such regional characteristics, let us simulate the economic and environmental effects when the CDM project is implemented in a certain region in 2000. The CDM investment is assumed to be implemented as shown in Table 3. Table 5 shows the results that we obtained in eight simulation cases. For example, the first row shows the case 
Table 3. Investment amounts of CDM projects (3,000 MW) by industry (Million RMB).

\begin{tabular}{rlr}
\hline & \multicolumn{1}{c}{ Sectors } & Investment \\
\hline 1 & Agriculture & 0.0 \\
2 & Mining & 0.0 \\
3 & Food & 0.0 \\
4 & Textile and wearing apparel & 0.1 \\
5 & Wooden products & 1.0 \\
6 & Paper and printing & 0.0 \\
7 & Chemical products & 0.0 \\
8 & Non-metallic mineral products & 0.0 \\
9 & Metal products & 0.3 \\
10 & Machinery & 862.2 \\
11 & Transport equipments & 41.3 \\
12 & Electric machinery & $1,254.9$ \\
13 & Other manufacturing products & 0.6 \\
14 & Electricity, gas and water supply & 0.0 \\
15 & Construction & $1,156.8$ \\
16 & Trade and transportation & 417.8 \\
17 & Services & 0.0 \\
\hline
\end{tabular}

Table 4. Output and emissions of $\mathrm{CO}_{2}$ and $\mathrm{SO}_{2}$ in 2000.

\begin{tabular}{|c|c|c|c|c|c|c|c|c|c|}
\hline & \multirow[b]{2}{*}{ Region } & \multicolumn{2}{|c|}{ Output } & \multicolumn{3}{|c|}{$\mathrm{CO} 2$} & \multicolumn{3}{|c|}{$\mathrm{SO} 2$} \\
\hline & & $\begin{array}{l}\text { Million } \\
\text { RMB }\end{array}$ & Share & $\begin{array}{l}\text { Mill. } \\
\text { ton-C }\end{array}$ & Share & $\begin{array}{c}\text { Intensity } \\
\text { (ton-C/mill. RMB) }\end{array}$ & 1000ton & Share & $\begin{array}{c}\text { Intensity } \\
\text { (ton/mill. RMB) }\end{array}$ \\
\hline A & North East & $1,947,259$ & $9.7 \%$ & 105.3 & $11.2 \%$ & 54.08 & 1223.7 & $13.3 \%$ & 0.63 \\
\hline B & North Municipalities & 941,944 & $4.7 \%$ & 51.0 & $5.4 \%$ & 54.17 & 607.0 & $6.6 \%$ & 0.64 \\
\hline $\mathrm{C}$ & North Coast & $2,849,491$ & $14.3 \%$ & 121.9 & $12.9 \%$ & 42.78 & 1432.1 & $15.6 \%$ & 0.50 \\
\hline $\mathrm{D}$ & Central Coast & $4,625,353$ & $23.1 \%$ & 133.9 & $14.2 \%$ & 28.96 & 1475.2 & $16.1 \%$ & 0.32 \\
\hline $\mathrm{E}$ & South Coast & $2,975,666$ & $14.9 \%$ & 63.5 & $6.7 \%$ & 21.35 & 733.9 & $8.0 \%$ & 0.25 \\
\hline $\mathrm{F}$ & Central Region & $3,497,790$ & $17.5 \%$ & 308.5 & $32.7 \%$ & 88.21 & 1981.1 & $21.6 \%$ & 0.57 \\
\hline G & North West & $1,122,470$ & $5.6 \%$ & 77.5 & $8.2 \%$ & 69.06 & 875.4 & $9.5 \%$ & 0.78 \\
\hline $\mathrm{H}$ & South West & $2,024,449$ & $10.1 \%$ & 82.4 & $8.7 \%$ & 40.71 & 848.9 & $9.3 \%$ & 0.42 \\
\hline & Total & $19,984,423$ & $100.0 \%$ & 944.1 & $100.0 \%$ & 47.24 & 9177.3 & $100.0 \%$ & 0.46 \\
\hline
\end{tabular}

where CDM investments are implemented in the North East region and the second row shows the case where CDM investments are implemented in the North Municipalities, and etc.

The first column shows the output inducement effects of CDM projects. We can see that the CDM projects bring relatively large economic effects when the projects are implemented in the 'Central Region', 'North Coast' and 'North East'. The second column is the standard deviation of output inducement effects for each region. In this paper, standard deviation of the increases in regional gross outputs induced by CDM projects is regarded as a proxy variable of income equalization effect. The standard deviation of induced regional gross outputs is relatively large in the case where CDM investments are implemented in such regions as 'Central Region', 'North Coast' and 'North East'. These regions, therefore, are not necessarily suitable as sites for CDM projects if 'income equalization' is a factor of high importance for the Chinese government as CDM approval criteria. The third column shows the employment effects of CDM projects. Since western rural areas such as the 'North West' and 'South West' are relatively labor intensive regions, CDM implementations in these areas bring relatively large induced effects in employment. The employment effect for the 'Central Region' is also considerably large.

The fourth and fifth columns show increases in emissions of $\mathrm{CO}_{2}$ and $\mathrm{SO}_{2}$ in the construction phase of $\mathrm{CDM}$ projects. It is in the 'Central Region' that has the largest effect on $\mathrm{CO}_{2}$ emissions followed by the 'North West' and 'North East', while the 'North West' has the largest increase in $\mathrm{SO}_{2}$ emissions followed by the 'North East' and 'Central Region'.

\section{Spillover Ratio of Innovation}

\subsection{Process innovation and product innovation ${ }^{10}$}

$\mathrm{CDM}$ is a transplantation of new technologies from developed countries to developing countries. Innovation effects are reflected by changes in the input coefficients in the framework of I-O analysis. There are two types of innovation; process innovation and product innovation. 
Table 5. Effects of CDM projects in the construction phase.

\begin{tabular}{llccccc}
\hline & & Output Total & Output & Employment & CO2 & SO2 \\
\hline & \multicolumn{1}{c}{ Region } & Million RMB & Standard deviation & 1000 persons & Mill. ton-C & 1000 ton \\
\hline A & North East & $10,140.1$ & 2673.0 & 250.2 & 0.62 & 6.70 \\
\hline B & North Municipalities & $6,364.8$ & 1613.1 & 100.1 & 0.45 & 4.94 \\
\hline C & North Coast & $10,264.8$ & 2741.5 & 299.0 & 0.53 & 5.79 \\
\hline D & Central Coast & $9,368.2$ & 2295.7 & 191.7 & 0.45 & 4.42 \\
\hline E & South Coast & $6,297.7$ & 1511.4 & 151.4 & 0.26 & 2.48 \\
\hline F & Central Region & $10,418.0$ & 2656.5 & 492.3 & 1.00 & 6.40 \\
\hline G & North West & $9,475.7$ & 2098.9 & 406.4 & 0.63 & 6.77 \\
\hline H & South West & $9,755.1$ & 2490.2 & 566.0 & 0.50 & 4.96 \\
\hline
\end{tabular}

- Process innovation: efficiency improvements in an industry. More output can be produced with the same amount of inputs. Process innovation implies a shift in the production function and the isoquant. Hence, the coefficients in the column are changed.

- Product innovation: efficiency improvements of inputs. In each of $\mathrm{n}$ production processes, the same amount of output can be obtained with a smaller amount of the product as an input. Hence, the coefficients in the row are changed.

Typical CDM investment considered in this research is, for example, improvement of production process for overall energy saving. Innovation with CDM project, therefore, is regarded as a process innovation. We focus on process innovation in this paper.

\subsection{Spillover coefficients of process innovation}

Innovation in industry $k$ is defined as shown in the following equation. The parameter $\alpha$ stands for the rate of innovation.

$$
\begin{aligned}
\bar{a}_{i k} & =(1-\alpha) a_{i k}(0<\alpha<1, i=1, \cdots, n) \\
\bar{a}_{i j} & =a_{i j}(i=1, \cdots, n \text { and } j \neq k)
\end{aligned}
$$

Supposing that $\mathbf{A}$ and $\overline{\mathbf{A}}$ respectively stands for an original input coefficient matrix and the one with improved efficiency, then the process innovation is expressed as follows.

$$
\overline{\mathbf{A}}=\mathbf{A}-\alpha\left(\mathbf{A} \mathbf{e}_{k}\right) \mathbf{e}_{k}^{\prime}
$$

The vector $\mathbf{e}_{k}$ is a unit column vector where element $k$ is one. Supply-demand balance after process innovation is expressed as follows. $\overline{\mathbf{B}}$ is an inverse matrix of Leontief corresponds to $\overline{\mathbf{A}}$.

$$
\overline{\mathbf{x}}=\overline{\mathbf{B}} \mathbf{f}
$$

CDM projects correspond to process innovation. The more resource consumption a CDM project can economize in the entire economy, the more effective the CDM is in the context of environmental conservation. The spillover effects of process innovation $s_{k}$ is defined as the ratio of the output change (decrease) that occurs in sectors other than the innovated industry $k$ in the whole output change (decrease) in the economy. In short, this is an indicator to see how much innovation in industry $k$ can economize outputs in industries other than industry $k$.

$$
s_{k}=\frac{\sum_{i \neq k}\left(\bar{x}_{i}-x_{i}\right)}{\sum_{i}\left(\bar{x}_{i}-x_{i}\right)}
$$

Using the formula for the inverse of a sum of matrices ${ }^{11}$ the difference of ex ante and ex post in Leontief's inverse matrix yields the following equation.

$$
\overline{\mathbf{B}}-\mathbf{B}=-\frac{\alpha}{1+\alpha \mathbf{e}_{k}^{\prime} \mathbf{B} \mathbf{A} \mathbf{e}_{k}} \mathbf{B}\left(\mathbf{A} \mathbf{e}_{k}\right) \mathbf{e}_{k}^{\prime} \mathbf{B}
$$

This equation can be further transformed since $\mathbf{B A}=\mathbf{B}-\mathbf{I}$.

$$
\overline{\mathbf{B}}-\mathbf{B}=-\frac{\alpha}{1+\alpha \mathbf{e}_{k}^{\prime}(\mathbf{B}-\mathbf{I}) \mathbf{e}_{k}}(\mathbf{B}-\mathbf{I}) \mathbf{e}_{k} \mathbf{e}_{k}^{\prime} \mathbf{B}
$$

The denominator of the right hand side is a scalar of $1+\alpha\left(b_{k k}-1\right)$ which shall be denoted as $\eta_{k}=1+\alpha\left(b_{k k}-1\right)$. And since $\bar{b}_{i j}-b_{i j}=\mathbf{e}_{i}^{\prime}(\overline{\mathbf{B}}-\mathbf{B}) \mathbf{e}_{j}$, each element of $\overline{\mathbf{B}}-\mathbf{B}$ is written as follows. 


$$
\begin{aligned}
\bar{b}_{i j}-b_{i j} & =-\alpha b_{i k} b_{k j} / \eta_{k} \\
\bar{b}_{k j}-b_{k j} & =-\alpha\left(b_{k k}-1\right) b_{k j} / \eta_{k}
\end{aligned}
$$

Let us compare ex ante output $\mathbf{x}=\mathbf{A x}+\mathbf{f}$ and ex post output $\overline{\mathbf{x}}=\overline{\mathbf{A}} \overline{\mathbf{x}}+\mathbf{f}$.

$$
\begin{aligned}
& \bar{x}_{i}-x_{i}=-\alpha b_{i k} \sum_{j} b_{k j} f_{j} / \eta_{k} \\
& \bar{x}_{k}-x_{k}=-\alpha\left(b_{k k}-1\right) \sum_{j} b_{k j} f_{j} / \eta_{k}
\end{aligned}
$$

The spillover effect of process innovation is defined as the ratio of the output change (decrease) that occurs in sectors other than the innovated industry $k$ in the total output change (decrease) in the economy. Let us define the sum of column $k$ of Leontief's inverse matrix $\mathbf{B}$ as $c_{k}$. Then, the spillover coefficient of process innovation $s_{k}$ is defined as follows.

$$
s_{k}=\frac{\sum_{i \neq k}\left(\bar{x}_{i}-x_{i}\right)}{\sum_{i}\left(\bar{x}_{i}-x_{i}\right)}=\frac{c_{k}-b_{k k}}{c_{k}-1}
$$

Note that the coefficient $s_{k}$ is independent of final demand $f_{j}$ or the innovation rate $\alpha$.

\subsection{Spillover rate of process innovation in China}

As equation (14) shows, $s_{k}$ depends on two factors; the overall backward linkage effect $c_{k}$ and the feedback effect to the own sector $b_{k k}$. As to the former factor, the larger is its overall backward linkage effect, the larger the spillover rate becomes. As to the latter factor, the larger is the industry's own input, the smaller the spillover rate becomes.

Table 6 shows the top 40 in 136(=17*8) 'industries*regions' whose spillover effect is large. The most conspicuous sector is 'construction' whose spillover effect for all regions is considerably large. This is because of the industrial feature of 'construction' that the backward linkage effect is large but the feedback from the own industry is small. Another notable sector would be 'Electricity, gas, \& water'. It is also imaginable that the own-input in the 'Electricity, gas, \& water' industry is so small that the spillover effect is large in comparison with other manufacturing sectors.

As is shown in Table 6, CDM projects in the North Municipalities or North Coast are preferable from the point of view of spillover effects suppose 'Electricity, gas, \& water' is a target of CDM projects in China.

\section{Net Environment Effects of CDM Projects}

\subsection{Environment effects of CDM projects in the operating phase}

A CDM project has two different effects; one is an economic effect in the construction phase and the other is an environmental effect through the resource saving functions of CDM plants/facilities. However, it is important to note that $\mathrm{CDM}$ projects have negative environment impacts in the construction phase, since the CDM investments consume additional natural resources including energy. Therefore, we need to offset these effects in order to evaluate the overall effects of a CDM project.

As is well known, China's main source of $\mathrm{SO}_{2}$ emissions is coal consumption and the largest coal consumer in China is the electric power generator. Japan's power generation technology is well-known for its high efficiency of energy conversion. Therefore, it is quite plausible that CDM projects are implemented in the power generating industry and technology is transferred from Japan to China. The average of annual increment of electric power capacity in China around the year 2000 was approximately 20,000 $\mathrm{MW}^{12}$. And we assume in this paper that coal-burning power plants whose nominal total capacity is $3000 \mathrm{MW}$, which is $15 \%$ of total increment, would be replaced as a CDM project in the year 2000.

According to a power plant specialist in a Japanese paper generator, the efficiency of power generation in Japanese is 20 to $30 \%$ higher than that in China. We, therefore, assumed the efficiency improvements by CDM would be $25 \%$. Therefore, the input coefficients of intermediate inputs in the electricity industry in the host region would decrease by this improvement rate. However, the CDM project we consider does not replace the whole capacity of power generation in the corresponding region. Then, we need to adjust the efficiency improvement rate by the relative scale of the CDM project ${ }^{13}$.

Table 7 shows the 'adjusted rate of improvement' in each region. Though the 'North Municipalities' is an exception, the improvement ratio is in the range of 1 to $2 \%$ reflecting the capacity of power generation of each region.

We assume the operating period would be ten years from 2001 to 2010. Ueta et al. (2005) discusses the macro effects of a CDM project in China and presents a macro projection for the Chinese economy. We used this estimation as the baseline forecast for a series of real final demand in the $r$ region, $\mathbf{f}_{r}{ }^{14}$. Supposing that $\mathbf{A}$ is an original input coefficient matrix and $\overline{\mathbf{A}}$ is an input coefficient matrix with improved efficiency, then economized total output $\mathbf{d} \mathbf{x}_{r}$ is expressed as follows: 
Table 6. Spillover rate: Top 40 in $136(=17 \times 8)$ 'Industries $\times$ Regions'.

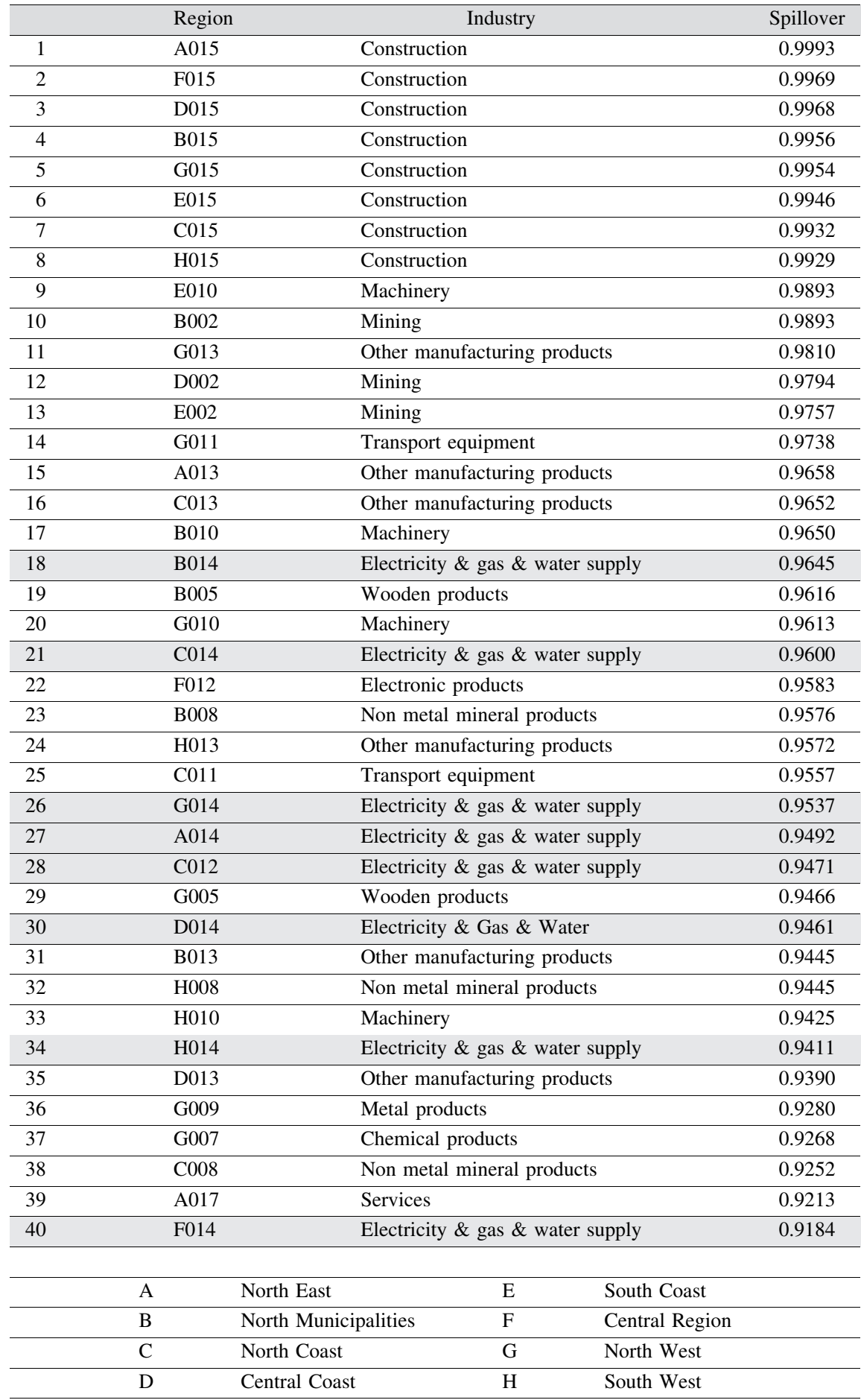

$$
\mathbf{d} \mathbf{x}_{r}=\mathbf{x}_{r}-\overline{\mathbf{x}}_{r}=\left[(\mathbf{I}-\mathbf{A})^{-\mathbf{1}}-(\mathbf{I}-\overline{\mathbf{A}})^{-\mathbf{1}}\right] \mathbf{f}_{r} .
$$

Assuming the symbol with the upper bar means that based on $\mathrm{CDM}$ technology, economized $\mathrm{CO}_{2}$ and $\mathrm{SO}_{2}$ emissions are also defined as follows.

$$
\begin{aligned}
& \mathbf{d c}_{r}=\mathbf{c}_{r}-\overline{\mathbf{c}_{r}}=\mathbf{C}\left(\mathbf{x}_{r}-\overline{\mathbf{x}}_{r}\right)=\mathbf{C} \cdot \mathbf{d} \mathbf{x}_{r} \\
& \mathbf{d \mathbf { s } _ { r }}=\mathbf{s}_{r}-\overline{\mathbf{s}_{r}}=\mathbf{S}\left(\mathbf{x}_{r}-\overline{\mathbf{x}}_{r}\right)=\mathbf{S} \cdot \mathbf{d} \mathbf{x}_{r}
\end{aligned}
$$

If we repeat this calculation for the decade of 2001-2010 and sum up all of the results, the environmental effects of CDM projects in the operating phase will be calculated as follows:

$$
\mathbf{t d c}_{r}=\sum_{t=2001}^{t=2010} \mathbf{d c}_{r t}
$$


Table 7. Adjusted efficiency improvement by regions.

\begin{tabular}{clc}
\hline & \multicolumn{1}{c}{ Region } & $\begin{array}{c}\text { Adjusted rate of } \\
\text { efficiency improvement }\end{array}$ \\
\hline A & North East & $1.97 \%$ \\
\hline B & North Municipalities & $7.65 \%$ \\
\hline C & North Coast & $1.48 \%$ \\
\hline D & Central Coast & $1.31 \%$ \\
\hline E & South Coast & $1.57 \%$ \\
\hline F & Central Region & $0.98 \%$ \\
\hline G & North West & $1.93 \%$ \\
\hline H & South West & $1.64 \%$ \\
\hline
\end{tabular}

Table 8. Environmental effects of CDM projects in the construction phase, operating phase and net effect.

\begin{tabular}{llcccrrr}
\hline & & \multicolumn{2}{c}{ Construction } & \multicolumn{2}{c}{ Operation } & \multicolumn{2}{c}{ Net effect } \\
\hline & & CO2 & SO2 & CO2 & SO2 & CO2 & SO2 \\
\hline & & $\begin{array}{c}\text { Mill. } \\
\text { ton-C }\end{array}$ & 1000 ton & $\begin{array}{c}\text { Mill. } \\
\text { ton-C }\end{array}$ & 1000ton & $\begin{array}{c}\text { Mill. } \\
\text { ton-C }\end{array}$ & 1000 ton \\
\hline A & North East & 0.62 & 6.70 & -2.62 & -32.19 & -2.01 & -25.49 \\
\hline B & North Municipalities & 0.45 & 4.94 & -2.87 & -37.64 & -2.43 & -32.69 \\
\hline C & North Coast & 0.53 & 5.79 & -2.19 & -27.65 & -1.66 & -21.86 \\
\hline D & Central Coast & 0.45 & 4.42 & -3.94 & -44.89 & -3.49 & -40.47 \\
\hline E & South Coast & 0.26 & 2.48 & -4.74 & -57.89 & -4.48 & -55.41 \\
\hline F & Central Region & 1.00 & 6.40 & -5.17 & -47.22 & -4.18 & -40.83 \\
\hline G & North West & 0.63 & 6.77 & -1.38 & -16.28 & -0.74 & -9.51 \\
\hline H & South West & 0.50 & 4.96 & -1.42 & -16.62 & -0.92 & -11.66 \\
\hline
\end{tabular}

Remark: net effect is not necessarily consistent because of rounding error.

$$
\mathbf{t d s}_{r}=\sum_{t=2001}^{t=2010} \mathbf{d s}_{r t}
$$

The first column of Table 8 shows the environmental effects of the construction phase which is the same content as shown in Table 5, and the second column of Table 8 shows the environmental effects in the operating phase of the $\mathrm{CDM}$ project. Concerning $\mathrm{CO}_{2}$ mitigation effects in the operating phase, the region that records the largest effect is the 'Central Region' followed by 'South Coast' and 'Central Coast'. Concerning $\mathrm{SO}_{2}$ reduction, reduction in the 'South Coast' is the largest, followed by 'Central Region' and 'Central Coast'.

\subsection{Net environmental effects of CDM projects}

As mentioned above, $\mathrm{CDM}$ investment brings an increase in emissions of $\mathrm{CO}_{2}$ and $\mathrm{SO}_{2}$ in the construction phase, although they will decrease in the operating phase. Therefore, we need to know the net reduction of $\mathrm{CO}_{2}$ and $\mathrm{SO}_{2}$ emissions in order to evaluate the environmental effects of the CDM project. That is to say, the net effect of CDM in reductions of $\mathrm{CO}_{2}$ and $\mathrm{SO}_{2}$ respectively are defined as "(18) minus (5)" and "(19) minus (6)".

$$
\begin{aligned}
& \mathbf{n c}_{r}=\mathbf{t d c}_{r}-\boldsymbol{\Delta} \mathbf{c}_{r} \\
& \mathbf{n s} \mathbf{s}_{r}=\mathbf{t d d} \mathbf{s}_{r}-\boldsymbol{\Delta} \mathbf{s}_{r}
\end{aligned}
$$

The net effects by region defined by (19) and (20) are shown in the two right most columns of Table $8^{15}$. It is clarified that there are big differences in the reduction of $\mathrm{CO}_{2}$ and $\mathrm{SO}_{2}$ depending on the locations of the CDM project. The region where the net reduction is largest for $\mathrm{CO}_{2}$ is the 'South Coast' followed by the 'Central Region', 'Central Coast' and 'North Municipalities'. And the 'South Coast', the region with the largest $\mathrm{CO}_{2}$ reduction, was able to reduce 4.48 Mill. ton-C, approximately six times as much as the reduction of 0.74 Mill. ton- $\mathrm{C}$ in the 'North West', the region with the smallest $\mathrm{CO}_{2}$ reduction. Similar results are observed concerning $\mathrm{SO}_{2}$ reduction. The 'South Coast', the region with the largest $\mathrm{SO}_{2}$ reduction, was able to reduce 55.41 kilo-ton, approximately six times as much as the reduction of 9.51 kilo-ton in the 'North West', the region with the smallest $\mathrm{SO}_{2}$ reduction.

It is one of the features of our study that the $\mathrm{CO}_{2}$ reduction in each region reflects the input structure of the power generation industry in the region. In other words, even if the scales or types of CDM projects are same, CER acquisitions are different among regions because of the difference in the location of the CDM projects. In summary, the simulation analysis suggests that the location of CDM projects should be determined cautiously, taking into account not only CER acquisition but also the size of the ripple effect the target industry has on other industries and other regions. 
Table 9. Rank of the site location in CDM.

\begin{tabular}{clccrc}
\hline & \multicolumn{2}{c}{ Point system } & \multicolumn{2}{c}{ Principal component } \\
\hline & \multicolumn{1}{c}{ Region } & Total point & Rank & Vector & Rank \\
\hline A & North East & 29 & 6 & -0.976 & 5 \\
\hline B & North Municipalities & 26 & 2 & 1.543 & 2 \\
\hline C & North Coast & 28 & 5 & -1.525 & 6 \\
\hline D & Central Coast & 27 & 4 & 0.673 & 3 \\
\hline E & South Coast & 26 & 2 & 4.093 & 1 \\
\hline F & Central Region & 20 & 1 & -0.106 & 4 \\
\hline G & North West & 30 & 7 & -1.582 & 7 \\
\hline H & South West & 30 & 7 & -2.119 & 8 \\
\end{tabular}

\section{Concluding remarks}

This paper considers which region is preferable as a location of CDM projects from the various points of view of socio-economic and environmental effects. Let us summarize several facts we observed in this paper.

- The 'Central Region' is preferred based on output increases in the CDM construction phase.

- The 'South Coast' is preferred based on the standard deviation of output increases in the CDM construction phase.

- The 'South West' is preferred based on the employment increases in the CDM construction phase.

- The 'North Municipalities' is preferred according to the technological spillover criterion.

- The 'South Coast' is preferred based on the net effects of the reduction of $\mathrm{CO}_{2}$ and $\mathrm{SO}_{2}$ emissions.

These results suggest that it is very difficult to determine the most suitable location for a CDM project. In other words, it is difficult to reconcile the profit-loss relationships among stake-holders concerning a CDM project.

However, we here attempt to compile these results into one variable to rank the regions in order. We apply two methods in order to make a rank order. The results are shown in Table 9. The first method is a 'point system', where each region is given a point of 8 to 1 based on the score for each criterion introduced in this paper ${ }^{16}$. This method eventually gives the same weight to all of the eight criteria to integrate the information. Judging from the overall score of these criteria, the most preferable region as a location for CDM is the 'Central Region' followed by the 'South Coast' and 'North Municipalities'. The 'Central Coast' is fourth.

Another method is an application of 'principal component analysis'. It is a multivariate analysis that is used to consolidate different kinds of information ${ }^{17}$. More specifically, principal component analysis finds the vector that has the maximum variance among any linear combinations of given vectors. Judging from the principal component analysis, the preferred region as a location for CDM is the 'South Coast' followed by the 'North Municipalities', 'Central Coast' and 'Central Region'.

Even though the two results are not necessarily identical, it turns out that the 'South Coast', 'North Municipalities', and 'Central Region', are candidates for the most suitable regions for CDM in comprehensively evaluating the criteria we cited in this paper. That is to say, that while China's government expects that CDM would be one measure to realize 'Great western development', our simulation suggests that CDM projects in more developed regions are more suitable in comprehensively evaluating socio-economic effects and environmental effects ${ }^{18}$.

Cooperation of the investing and host countries is indispensable to the implementation of a CDM project. However, most of researches on CDM see the effects of CDM from the viewpoint of the Annex I countries ${ }^{19}$ (investing countries) while they rarely emphasize the viewpoints of developing countries. Therefore, we believe that this paper is unique because this paper provides profitable information for the host country.

Since the Kyoto Protocol came into force on 16 February 2005, Annex I countries have to achieve their reduction targets in the commitment period 2008 to 2012 . However, it is said that the domestic measures would not be enough for Japan to achieve the target of Kyoto Protocol; therefore it would be inevitable for Japan to make use of the Kyoto mechanism. We also believe that the information in this paper would be useful when Japanese firms negotiate with the Chinese government.

\section{Notes}

${ }^{1}$ Clean development mechanism (CDM) is one of the flexibility mechanisms in Kyoto Protocol. And CDM has such two objectives as efficient reduction of Greenhouse Gas (GHG) emissions and contribution to the sustainable development of host countries.

2 It seems that the original data of China MRIO of IDE were collected in 30 sector basis. However, in the published data in the report (IDE(2003)), the largest table is 17 sector basis. We, therefore, used 17 sector IO table in this research.

3 Since the I-O table we used is of 17 sectors with 8 regions, the size of the input coefficient matrix and the Leontief's inverse matrix is 136 by 136. 
${ }^{4}$ For example $r$ means the 'North West', the 'North West' part of the vector $\Delta \mathbf{f}_{r}$ contains positive numbers and the other elements are zero.

5 A supplement table of the Ministry of Internal Affairs and Communications of Japan (2004).

${ }^{6}$ For details, see Ueta et al. (2005).

7 All the coals dug out in a certain region, of course, are not necessarily consumed in the same region. However, there is no data showing that each power plant uses what kind of coals. And it would be natural that most of coals consumed in a power plant are from neighboring region taking the distribution cost of coals into account. We, therefore, used the sulfur content rates of the coals in the same region as the power plant exists as a approximation.

8 There is no reliable statistics concerning operation of desulfurization equipment though a few power plants in China recently began to introduce desulfurization equipment. In addition, it is said that desulfurization equipment scarcely operates even if it is set up.

9 This concentration of economic power is a reflection of a policy of foreign capital introduction to the coastal region.

10 Description in this section is based on Dietzenbacher (2000).

11 See Henderson and Searle (1981).

12 See Hama (2006). Also, according to Xing Ying (2004), the government plan for annual increment of electric power capacity up to 2010 in China is approximately 30,000 MW.

13 For example, the capacity of the power plant invested as CDM is $10 \%$ of total capacity in the corresponding region, the adjusted efficient improvement rate is $2.5 \%$ (25\% times 0.1$)$.

14 According to the prediction of Ueta $e t$ al. (2005), the growth rate of real private consumption, real investment, real export, and real GDP for 200-2010 would be $6.2 \%, 6.5 \%, 9.1 \%$ and $6.8 \%$, respectively. We assumed that final demands of all the regions would increase identically at those growth rates.

15 In the meantime, estimated $\mathrm{CO} 2$ reduction in our research would be larger than CER obtained by the current rule for CDM. This is because our research considers the overall effects including ripple effects to other industries, while CER obtained by CDM focuses on only the direct effects in the establishment of the actual CDM project.

16 The region of the first place gets 8 points and the region of the last place gets 1 point.

17 See for example Theil (1971) section 1.9. In this paper, we used vectors after normalization.

18 This is a tentative conclusion that can differ according to the criteria taken into account.

19 The countries that signed Annex I of the United Nations Framework Convention on Climate Change (UNFCCC) are called Annex I parties or Annex I countries. Annex I parties include such industrialized countries as OECD members as of 1992, the Russian Federation, the Baltic States, and several Central and Eastern European States. Kyoto protocol signed in the third conference of UNFCCC (COP3) stipulates that Annex I countries should reduce greenhouse gas (GHG) emissions by $5 \%$ comparing with 1990 emission level.

\section{REFERENCES}

Dietzenbacher, E. (2000), "Spillovers of Innovation Effects," Journal of Policy Modeling, Vol. 22, No. 1, pp. $27-42$.

Hama, K. (2006), "China energy crisis brought change for energy conservation development strategy," Soka University Bulletin of Chinese Studies, Soka University, Vol. 9, pp. 1-47 (in Japanese).

Henderson, H. V., and Searle, S. R. (1981), "On Deriving the Inverse of a Sum of Matrices," Siam Review, Society for Industrial and Applied Mathematics, Vol. 23, No. 1, pp. 53-60.

Institute of Developing Economies (2003), Multi-Regional Input-Output for China 2000, Statistical Data Series No. 86, Institute of Developing Economies, Tokyo.

Leontief, W. (1966), Input-Output Economics, Oxford University Press, New York.

Ministry of Internal Affairs and Communications of Japan (2004) Input-Output table in Japan, 2000.

National Bureau of Statistics of China (2001). China Statistical Yearbook 2001, China Statistics Press.

National Bureau of Statistics (Department of Industry and Transport Statistics) and National Development and Reform Commission of China (eds.) (2005), China Energy Statistical Yearbook 2000-2002, China Statistics Press.

National Institute of Science and Technology Policy (ed.) (1992), The Global Environment and Energy Use in Asia, Ministry of Finance Press, Tokyo. (in Japanese).

OECD, 2003. OECD Environmental Indicators: Development, Measurement and Use. Downloadable at http://www.oecd.org/ env/indicators.html.

Okamoto and Ihara (eds.) (2004), "Spatial structure and regional development in China: International input-output approach," IDE development perspective series No. 5, Institute of Developing Economies, Tokyo.

Theil, H. (1971), Principles of econometrics, Wiley, New York.

Ueta et al. (2005), "Win-win strategy for Japan and China in climate change policy.” Downloadable at http://www.esri.go.jp/ jp/prj-2004_2005/kankyou/kankyou16/09-2-R.pdf.

Ueta et al. (2006), "Comprehensive Analysis and Evaluation of CDM Projects in China." Downloadable at http://www.esri.go.jp/jp/prj-2004_2005/kankyou/kankyou17/04-1-R-1.pdf.

Xing, Y. (2004), "present situation and future outlook of China's electricity demand and supply" Overseas Electric Power, Japan Electric Power Information Center, September, pp. 34-39. (in Japanese). 